\title{
Microplastics in surface water and sediments of Chongming Island in the Yangtze Estuary, China
}

Yubo Li ${ }^{1,2}$, Zhibo Lu ${ }^{1,2^{*}} \mathbb{D}$, Hongyuan Zheng ${ }^{1,2}$, Juan Wang ${ }^{1,2}$ and Cheng Chen ${ }^{3}$

\begin{abstract}
Background: The Yangtze Estuary acts as gateways where microplastics transport from freshwater into marine environments, with one of the largest discharge volumes in the world. The occurrence of microplastics in surface water and sediments of the Yangtze Estuary has been reported. However, little is known about microplastics in and around Chongming Island in the estuary. In this study, the distribution of microplastics in surface water and sediments of Chongming Island was investigated and compared in different environmental medium.

Results: Abundances of microplastics in surface water and sediments were in the ranges of 0-259 items $\mathrm{m}^{-3}$ and 10-60 items $\mathrm{kg}^{-1}$ dry weight, respectively. Microplastics were more abundant in the surface water of the Yangtze River shores than in the inland rivers $(p<0.01)$. Proportions in fiber form in surface water and sediment were $33 \%$ and $67 \%$; and those in fragment form were $39 \%$ and $24 \%$. Most particles ( $>72 \%$ ) were $<1 \mathrm{~mm}$ in the longest dimension; $65 \%$ were white and $30 \%$ were transparent. Of the 11 compositions identified, polyethylene, polypropylene, and a-cellulose predominated in both phases.
\end{abstract}

Conclusion: This is the first study to focus on microplastics in inland watercourses on Chongming Island and along the Yangtze River's shores in both phases. There were differences between the island and estuary in composition and density due to the distinct vertical mixing processes. The in situ filtration of surface water $(100 \mathrm{~L})$ sampling method was well employed in various freshwater environments and free of plastic materials in front of the filter, analysis results of which provided an important baseline reference for evaluating microplastic pollution in the Yangtze Estuary.

Keywords: Microplastics, Yangtze Estuary, Chongming Island, Surface water, Sediment

\section{Background}

Plastics have become indispensable due to their lightness, flexibility, cheapness, and long service life, with global production reaching 360 million tons in 2018 [1]. The term 'microplastics' refers to plastic particles of $<5 \mathrm{~mm}$ in size [2]. Their presence in the environment has been reported since the early 1970s [3], and many studies since have shown that microplastics are now ubiquitous in the oceans at all depths $[4,5]$, from the Arctic [6] to the

\footnotetext{
*Correspondence: luzhibo@tongji.edu.cn

${ }^{1}$ College of Environmental Science and Engineering, Tongji University,

Shanghai 200092, China

Full list of author information is available at the end of the article
}

Antarctic [7]. Most studies have focused on microplastics in marine systems, with $<4 \%$ of publications concerning freshwater systems [8]. Oceanic plastic debris mainly originates from the land, where innumerable plastic particles and fibers accumulate [9]. Microplastics enter freshwater environments through various routes including discharge of domestic wastewater [10], application of sludge from wastewater treatment plants in agriculture [11], landfill leachate [12], surface run-off (little is known about transport by run-off), and atmospheric deposition [13]. Previous studies have shown that once in the aquatic environment, microplastics are ingested by a range of organisms, with further impact due to the leaching of toxic plastic additives including bisphenols and 
phthalates $[14,15]$. As for processes, there is insufficient understanding of appropriate sampling and analysis techniques for microplastics in freshwater [9], with variations in methodology hindering comparisons of study results. Sampling methods may involve either small-volume or bulk sampling, while analysis methods mainly include the use of spectroscopic instruments and identification by a microscope or the naked eye [16].

The Yangtze Estuary is considered to be the largest contributor of plastic to the ocean in global modeling studies [17], and thus it has raised the level of concern. Several studies have separately reported the occurrence of microplastics in surface water or sediment of the Yangtze Estuary, and different volumes of samples were collected and analyzed. A total of 43 water samples ( $5 \mathrm{~L}$ per sample) from the Yangtze River and the East China Sea were analyzed with average abundance around 900 items $\mathrm{m}^{-3}$ [18]. By using a Teflon pump and neuston trawls to sample 12-20 L water in the Yangtze Estuary, Zhao obtained a range of microplastic abundances from 500 to 10,200 items $\mathrm{m}^{-3}$ [19]. Zhao collected $100 \mathrm{~L}$ water samples during the ebb phase and reported the overall mean microplastic abundance was $157.2 \pm 75.8$ items $^{-3}$ [20]. After analyzing $100 \mathrm{~g}$ sediment, Peng reported that the mean concentration of microplastics in surface sediments of the Yangtze Estuary was $121 \pm 9$ items $\mathrm{kg}^{-1}$ dry weight [21]. Additionally, previous studies have assessed the environmental risk of microplastics and re-estimated the riverine plastic load of the Yangtze River [20, 22]. Chongming Island, with its densely distributed river network, is situated in the middle of the Yangtze Estuary, but it is still unclear whether there exists microplastic pollution, particularly how it compared to the Yangtze Estuary.

This study investigates the distributions of microplastics in surface water and sediments in the Yangtze River and inland watercourses of Chongming Island at the river's mouth. Surface water samples were collected using a modified bulk-sampling method. Microplastics were characterized by quantity, shape, color, and size using a stereoscopic microscope, and their compositions were determined by micro Fourier-transform infrared spectroscopy ( $\mu$-FTIR). Here, we present comparable data for microplastics in the rivers of estuarine island and nearshore waters of the Yangtze River's downstream.

\section{Methods}

\section{Study area and sampling sites}

The Yangtze River flows through 11 provinces and cities, entering the East China Sea at Shanghai. Its estuary divides into north and south branches around Chongming Island, the largest alluvial island in the world, located north of Shanghai city. Approximately 70 thousand people live on the largely flat island, whose the river drainage system is controlled by culverts and sluice gates. During drainage periods, the influence of tides allows the river network to draw water from the Yangtze River through open sluice gates on the southern side of the island, then the gates on the northern side are opened to discharge water. The gates are closed during non-drainage periods, isolating the island's rivers from the Yangtze and forming an almost closed water system. The gate control system contributes directly to the lack of river hydrodynamics.

This study considers two E-W flowing rivers (the Nanhengyin and Beihengyin), six N-S rivers (the Gelong, Laoyao, Xinhe, Buzhen, Siyao, and Bayao) on Chongming Island, and both branches of the Yangtze River. Sampling was undertaken continually during June 21-23, 2019, when the gates were in the closed state. Fifteen sets of surface water and sediment samples were collected; nine from inland island rivers and six from the Yangtze River shores along the island during the ebb phase, representing the microplastic pollution situation of the Yangtze Estuary. Detailed information about the sampling sites is shown in Additional file 1: Table S1 and Fig. S1.

\section{Sample collection and processing}

A modified surface-water sampling method was used as follows. An empty metal cylinder (volume, $575 \mathrm{~mL}$; $\Phi=7 \mathrm{~cm}, H=15 \mathrm{~cm}$ ) was immersed in water with its exterior attached to floats to keep the top at a depth of $5 \mathrm{~cm}$. The open top (water inlet) had a coarse screen with an average mesh size of $\sim 1 \mathrm{~cm}$, and a metal filter of $300 \mu \mathrm{m}$ mesh size was placed across the middle of the cylinder. The cylinder bottom was connected to a centrifugal pump, which drew at least $100 \mathrm{~L}$ of surface water with a flow rate of $0.2 \mathrm{~L} \mathrm{~s}^{-1}$ through the cylinder at each sampling site. After sampling, the metal filter was transferred and stored in a sealed metal container pending analysis. Plastic components were avoided in front of the metal filter, and all components were thoroughly washed with distilled water before sampling. Sediment samples were collected at the same sampling site of $1 \mathrm{~m}^{2}$ quadrats from the upper $5-10 \mathrm{~cm}$ of the riverbed, using a sediment core sampler. Replicate samples (600-800 g) were taken from three randomly chosen points at each sampling site, then placed in aluminum foil bags and homogenized. All sediment samples were stored at $4{ }^{\circ} \mathrm{C}$ pending analysis.

In the laboratory, samples were processed based on previous criteria, with little modifications [21]. Metal filters were oven-dried at $60{ }^{\circ} \mathrm{C}$ for $24 \mathrm{~h}$ and sediment samples were dried at $75{ }^{\circ} \mathrm{C}$ for $72 \mathrm{~h}$ to constant weight. $200 \mathrm{~g}$ of each dried sediment sample was placed in a 1 $\mathrm{L}$ glass beaker, and $500 \mathrm{~mL}$ of saturated $\mathrm{NaCl}$ solution (density $1.20 \mathrm{~g} \mathrm{~cm}^{-3}$ ) was added. The mixture was manually stirred for $2 \mathrm{~min}$, and after settlement for $2 \mathrm{~h}$ the 
suspension was decanted in a $150 \mathrm{~mL}$ beaker. Organic matter in the suspension was degraded by treatment with $20 \mathrm{~mL} 30 \% \mathrm{H}_{2} \mathrm{O}_{2}$ at $65{ }^{\circ} \mathrm{C}$ for $24 \mathrm{~h}$, and the solution was filtered under vacuum through a $75 \mu \mathrm{m}$ nylon filter. The filters were dried for further analysis. The metal filters were not subjected to digestion processes, as these could have negative impacts such as bleaching and the addition of organic materials [23]. However, it was necessary to treat the sediment samples with peroxide because floatation carries large amounts of impurities from the sediment, leading to difficulties in performing analyses on nylon filters compared with relatively 'clean' metal filters.

\section{Sample analysis}

The dried filters were studied using a Nikon SMZ25 Stereo Microscope (Nikon, Tokyo, Japan) coupled with imaging software (NIS-Elements 4.60.00; Nikon). Suspected microplastic particles were counted on the basis of structural integrity when touched or moved by tweezers, avoiding those with biological structures [23]. Each filter was scrutinized by two or three observers, with the quantity, shape, color, and size of items being recorded. Abundances were recorded as items $\mathrm{m}^{-3}$ water and items $\mathrm{kg}^{-1}$ dry sediment, and shapes were categorized as fiber, fragment, film, or granule. Microplastics were measured using the imaging software and classified according to their longest dimensions as 75-300, 300-1000, $1000-2000$, or $2000-5000 \mu \mathrm{m}$, in view of the ingestion of microplastics by aquatic organisms [24].

The $\mu$-FTIR analyses involved a Nicolet TM iNTM10 FTIR system (Thermo Fisher Scientific, USA) equipped with a single-element mercury cadmium telluride detector. Transmittance mode was used, with each particle compressed in a diamond anvil compression cell. Spectrum acquisition involved 32 scans per replicate over a bandwidth of $4000-675 \mathrm{~cm}^{-1}$ at a resolution of $4 \mathrm{~cm}^{-1}$. Spectra were processed by OMNIC ${ }^{\mathrm{TM}}$ Specta $^{\mathrm{TM}}$ software and compared with spectral libraries (including Aldrich Polymers, Hummel Polymer and Additives, Polymer Additives and Plasticizers, Sprouse Polymer Additives, and Synthetic Fibers by Microscope).

\section{Quality assurance and quality control}

Special precautions were given to prevent contamination during the whole procedures. Non-plastic components were used wherever possible. Contamination was prevented by rinsing all containers three times with distilled water and drying before their first use. All of the filters were rinsed and heated at $450{ }^{\circ} \mathrm{C}$ for $8 \mathrm{~h}$ to eliminate any organic materials. The measures for contamination prevention during transportation are specified in Additional file 1: Fig S2. The laboratory was sealed during sample handling and analyses to avoid airborne contamination, and cotton lab coat and gloves were worn at all times. Filters and solutions were always covered by aluminum foil during drying and suspension process.

Blank experiments should be conducted to examine potential contamination by running parallel the same processing with the samples. $1 \mathrm{~L}$ of distilled water, $1 \mathrm{~L}$ of saturated $\mathrm{NaCl}$ solution, and $100 \mathrm{~mL}$ of $30 \% \mathrm{H}_{2} \mathrm{O}_{2}$ were filtered, and laboratory air was pumped under vacuum for $1 \mathrm{~h}$ with two operators present. The filter used above was $75 \mu \mathrm{m}$ nylon filter, which was left in covered containers and analyzed. If there were microplastics detected on the filter, then they should be deducted from the final values. In this study, two groups of blank experiments were conducted with no microplastics were found, but two natural fibers were identified on the filter (Additional file 1: Table S2).

\section{Statistical analysis}

Statistical analysis involved the IBM Statistic Package for Social Science (SPSS) 24. Pearson correlation coefficients $(r)$ were calculated for the relationship between microplastic abundances in surface water and sediment, with the significance of differences between the groups being determined by the Mann-Whitney $U$ test (significance level 0.05). Principal component analysis (PCA) was undertaken using a data matrix of polymer types found at each sampling site to evaluate the relationship between microplastic compositions and sampling sites.

\section{Results}

\section{Abundance and distribution of microplastics}

Totals of 51 and 105 microplastics were identified in surface water and sediments, with abundances range of 0.0 25.9 items per $100 \mathrm{~L}\left(0.0-258.9 \mathrm{~m}^{-3}\right)$ and $2-12$ items per $200 \mathrm{~g}$ dry weight (d.w., $10-60$ items $\mathrm{kg}^{-1}$ d.w.), respectively (Additional file 1: Table S1). Sampling sites on Chongming Island can be divided into two groups: group YRS (Yangtze River shores) including six sites along the island shorelines (sites Y1-Y6), and group ILR (inland rivers) including nine sites from six main inland rivers on Chongming Island (sites M1-M3 and C1-C6), representing microplastic pollution from land-based sources. Average microplastic abundances (mean \pm standard deviation) in surface water and sediments of groups YRS and ILR were $67.5 \pm 94.4$ items $^{-3}$ and $28.3 \pm 14.4$ items $\mathrm{kg}^{-1}$; and $9.8 \pm 12.2$ items $\mathrm{m}^{-3}$ and $39.4 \pm 16.1$ items $\mathrm{kg}^{-1}$, respectively. An overview of the distribution of microplastics on Chongming island and in the Yangtze River Estuary is given in Fig. 1.

Microplastics were found in the sediment at every sampling site, and there were no statistically significant differences in microplastic abundances between the two groups (Mann-Whitney $\mathrm{U}$ test, $p=0.224$ ). The highest 


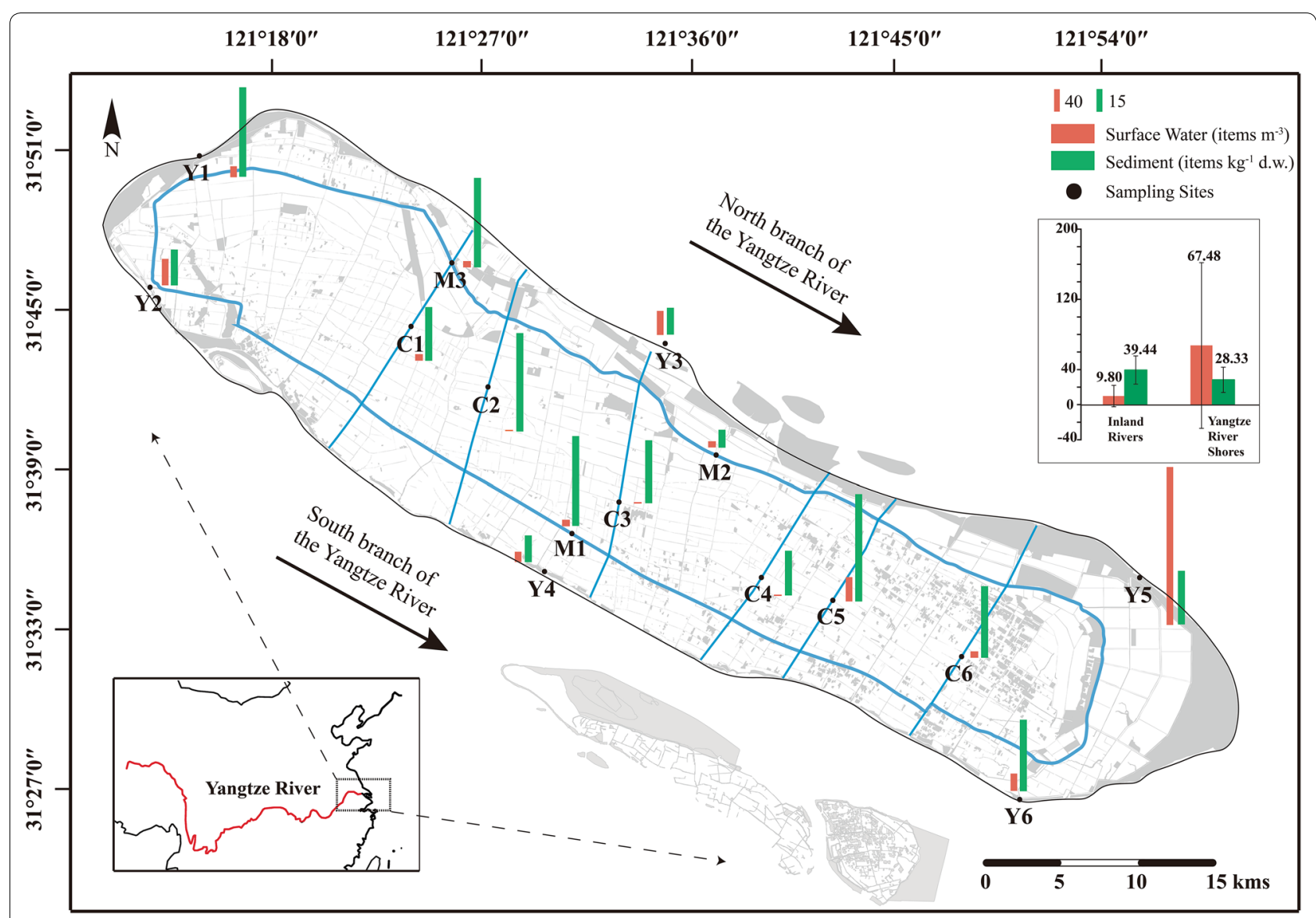

Fig. 1 Spatial distribution of microplastic abundances in surface water and sediments of the Yangtze Estuary

abundance of microplastics in sediments was found at site C5 (60.0 items $\mathrm{kg}^{-1}$ d.w.). There is an aquaculture market near $\mathrm{C} 5$, and therefore the long-term use and unintentional disposal of plastic products may result in accumulation of microplastics within this area. Other higher abundances in group ILR (50-60 items $\mathrm{kg}^{-1}$ ) were collected at site M1 and M3, which were characterized by increasing human activities.

In surface water, however, microplastics were more abundant in group YRS, with the difference being significant (Mann-Whitney $\mathrm{U}$ test, $p=0.005$ ). The highest abundance of microplastics in surface water (258.9 items $\mathrm{m}^{-3}$ ) was found on northeastern Chongming Island at site Y5, which may partly be explained by the special topography near the north branch and tide interact in the Yangtze Estuary [25]. The second highest abundance (43.4 items $\mathrm{m}^{-3}$ ) was at site $\mathrm{Y} 2$, near the Chongxi sluice gate in the western Chongming Island. There the external and internal gates are linked to the Yangtze River and intake channel, respectively, with the potential to influence microplastics transportation in the surrounding waters. No microplastics were found in surface water at three sampling sites (C2, $\mathrm{C} 3$, and $\mathrm{C} 4)$, possibly due to the low level of human activity in the middle part of Chongming Island. Correlations of microplastic abundances in both phases of all sites were not statistically significant (Pearson's correlation, $p>0.05$ ).

\section{Shape, color, and size of microplastics}

The morphological characteristics of the observed microplastics are summarized in Fig. 2. Fragments were the predominant shape in surface water with an average proportion of $39.2 \%$, dropping to $23.8 \%$ in sediments. Fiber proportions were higher in sediments (average 66.7\%) than those in surface water (33.3\%). The proportion of films decreased from $19.6 \%$ in surface water to $9.5 \%$ in sediments. Granules were the least frequent shape, accounting for $7.8 \%$ and $0.0 \%$ in surface water and sediment, respectively (Fig. 2a). Typical shapes of microplastics from all samples are summarized in Fig. 3.

Eight colors (white, blue, transparent, yellow, black, red, brown, and green) were observed in microplastics in surface water and sediment (Fig. 2b), with white being the most common in surface water $(64.7 \%$; cf. $11.4 \%$ in 

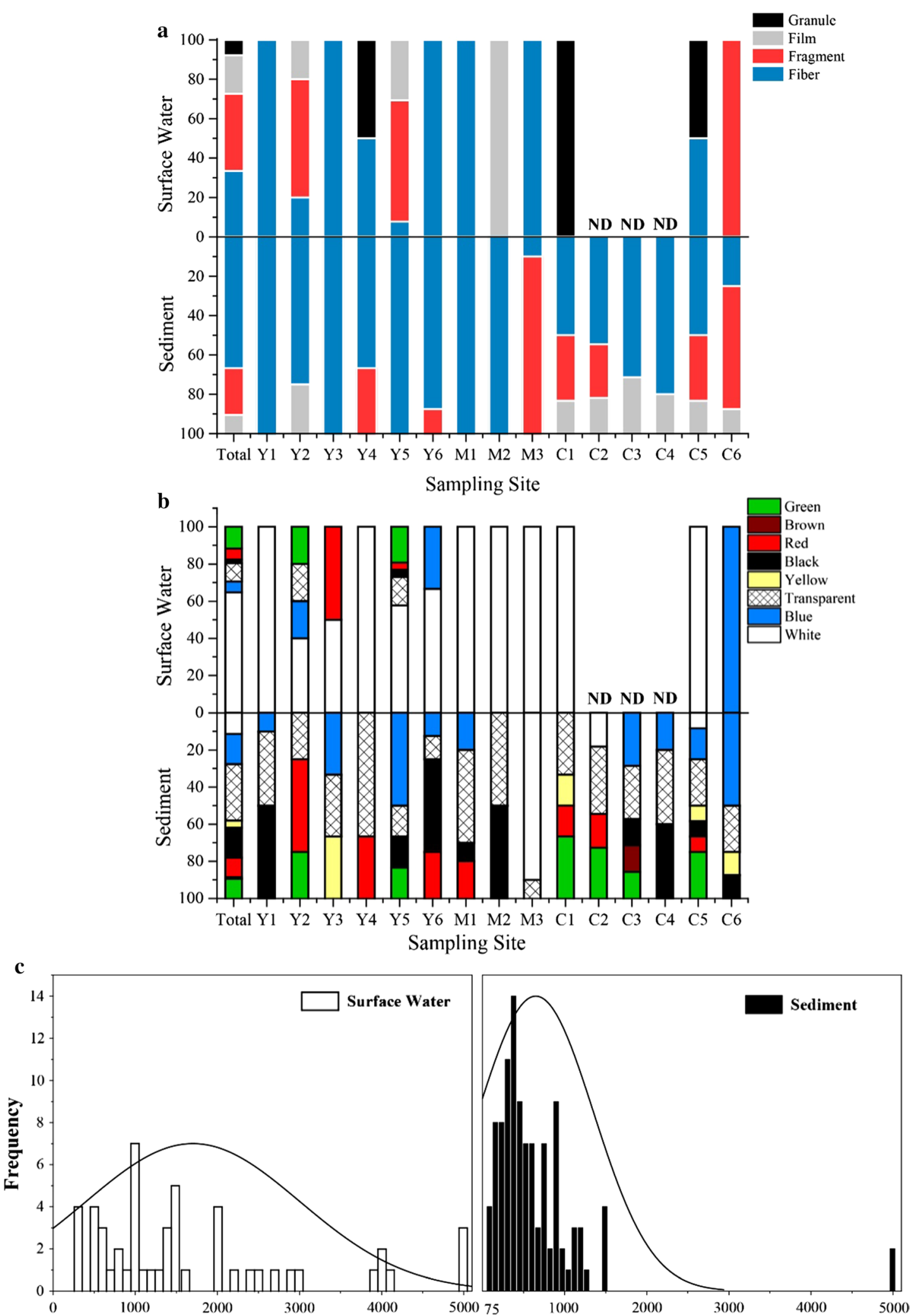

Fig. 2 Cumulative percentages of microplastics colors (a), microplastics shapes (b) and normal frequency distribution across different size categories (c) of total microplastics in two phases. ND means not detectable 

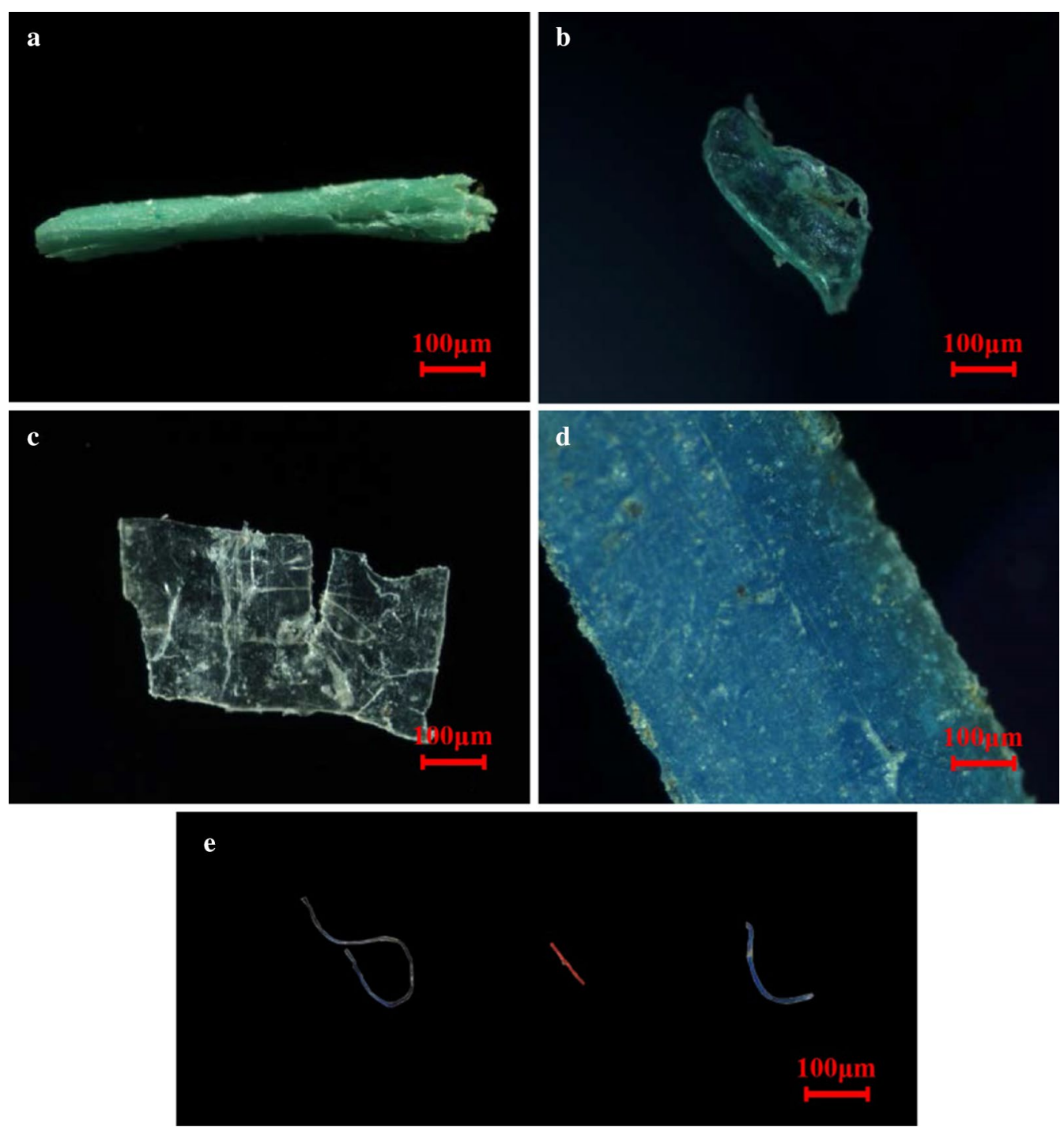

Fig. 3 Microscope images of typical microplastics. Fragment (a, b); film (c, d); fibers (e)

sediment). Transparent particles were most common in sediments (16.2\%; cf. 9.8\% in water). A large number of transparent plastics are commonly used in fishing nets and lines for the frequent fishery activities in Shanghai [21], and transparent microplastics in sediment samples may be attributed to the bleaching caused by digests.

The lower limit of microplastics size was $300 \mu \mathrm{m}$ in surface water and $75 \mu \mathrm{m}$ in sediments, as dictated by different filters. Most microplastics in both phases were $<2000 \mu \mathrm{m}$ in size, whereas the large microparticles $(2000-5000 \mu \mathrm{m})$ were seldom observed (Fig. 2c). In surface water, microplastics possessed the wide size distribution from $300 \mu \mathrm{m}$ to $4000 \mu \mathrm{m}$ (Fig. 2c), meanwhile the size of most microplastics valued less than $1000 \mu \mathrm{m}$ (Fig. 2d). A possible explanation is that large plastics are prone to forces of flow and wind leading to floating on water, while smaller plastics tend to migrate into sediments and deep water [26, 27]. Size distribution of group YRS and ILR in both phases is shown in Additional file 1: Table S3.

\section{Identification of microplastics}

Suspected microplastic particles were analyzed by $\mu$-FTIR, which has been widely employed in identifying microplastic polymers due to its high reliability in determining chemical compositions of unknown plastic fragments [16, 28]. Composition-library comparisons were difficult to achieve with high similarities due to the weathering and contamination of plastics [29], with the lower limit being set relatively high here (>75\%) to 
provide more accurate results (compared with $60 \%-80 \%$ in previous studies). Eleven polymer types were identified: polyethylene (PE), polypropylene (PP), $\alpha$-cellulose,

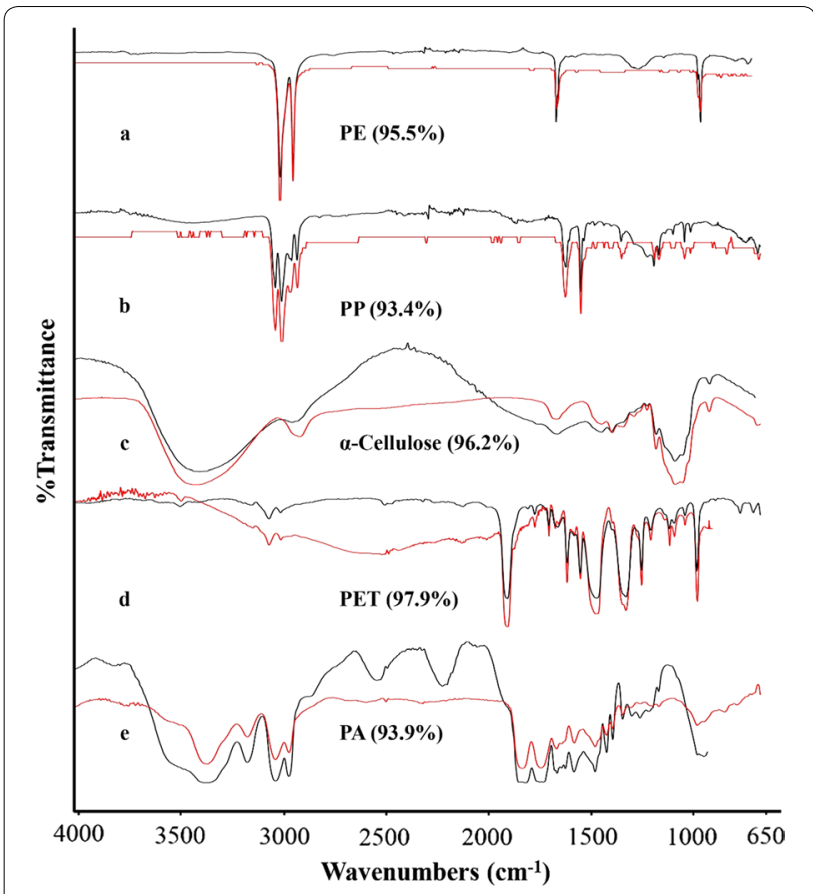

Fig. 4 FT-IR spectra and match degrees of selected items. Red curves are FTIR spectra of standard polymers in spectral libraries, and black curves are FTIR spectra of microplastics samples polyethylene terephthalate (PET), cellulose acetate (CA), polyamide (PA), polybutene (PB), polymethyl methacrylate (PMMA), cellophane, polyurethane (PU), and ethylene/ethyl acrylate (EEA). FTIR spectra of the five most common types are shown in Fig. 4, and relative compositions are given in Fig. 5. The predominant polymer type in surface water was $\mathrm{PE}(37.3 \%)$, and that in sediment was PP (28.6\%). PE and PP were the most abundant polymer types in both phases, and these are also the leading polymers in plastics production. In 2018, PP (19.3\%), low-density PE (17.5\%), and high-density PE (12.2\%) were the predominant resin types used widely in packaging and construction [1]. Another common microplastic, $\alpha$-cellulose, used mostly in clothing, had proportions of $27.5 \%$ in surface water and $24.8 \%$ in sediments, but such semi-synthetic fibers had lower search scores (most $<80 \%$ ) and were difficult to accurately recognize. The characteristic spectral band at $1105 \mathrm{~cm}^{-1}$ was used to distinguish semi-synthetic and natural fibers [30]. Color uniformity and average shape were also considered when it was otherwise difficult to identify the composition of fibers.

PCA results indicate that 11 variables (i.e., 11 polymer types) described the spatial distribution of sampling sites in three-dimensional coordinates. Figure 6a shows the PCA of the 7 variables in surface water, with PC1, $\mathrm{PC} 2$, and $\mathrm{PC} 3$ explaining $>92.66 \%$ of the total variance (Component matrix and component plot are shown in Additional file 1: Table S4 and Fig. S3). PC1, explaining

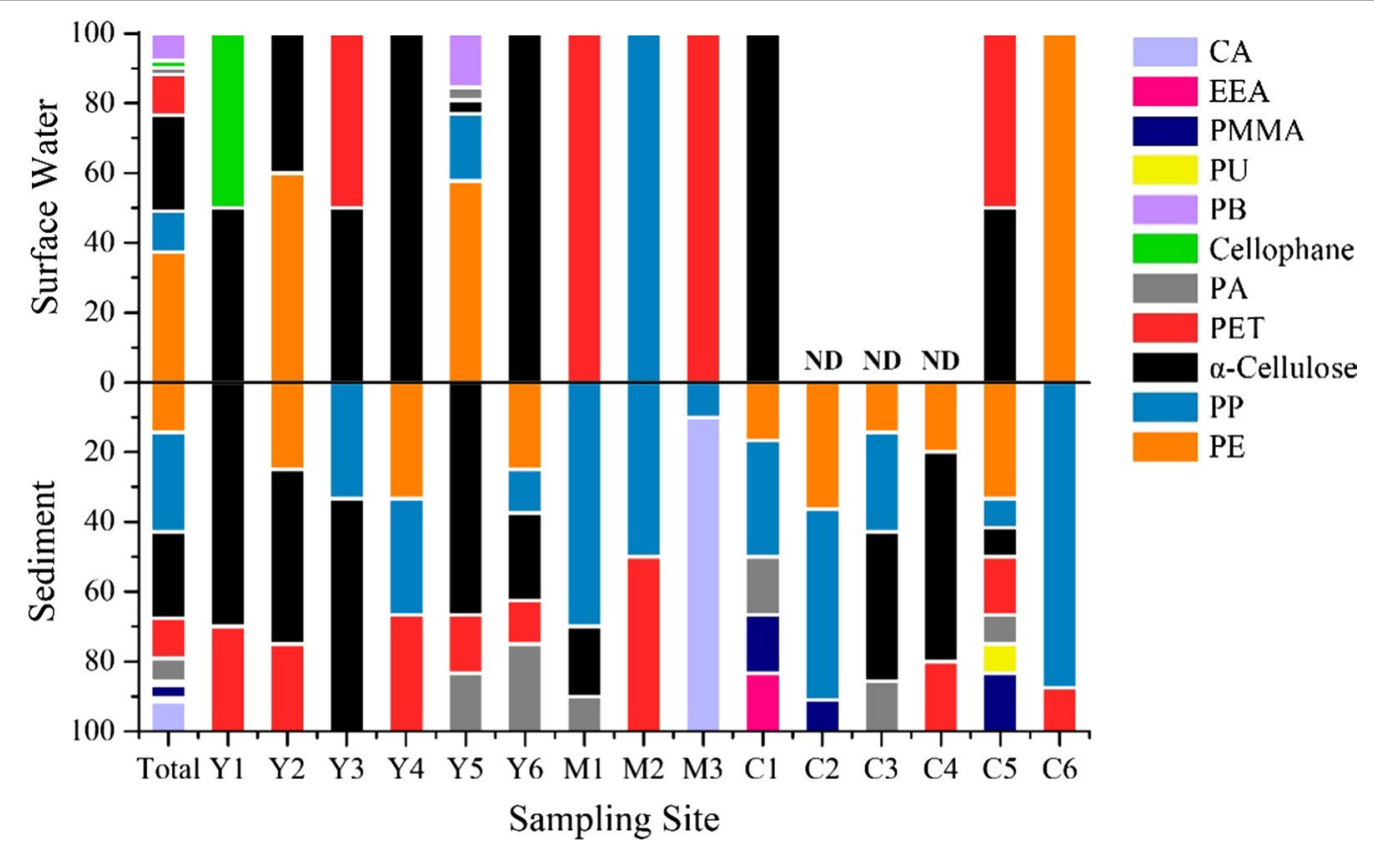

Fig. 5 Cumulative percentages of microplastic compositions in surface water and sediments of the Yangtze Estuary. ND means not detectable 

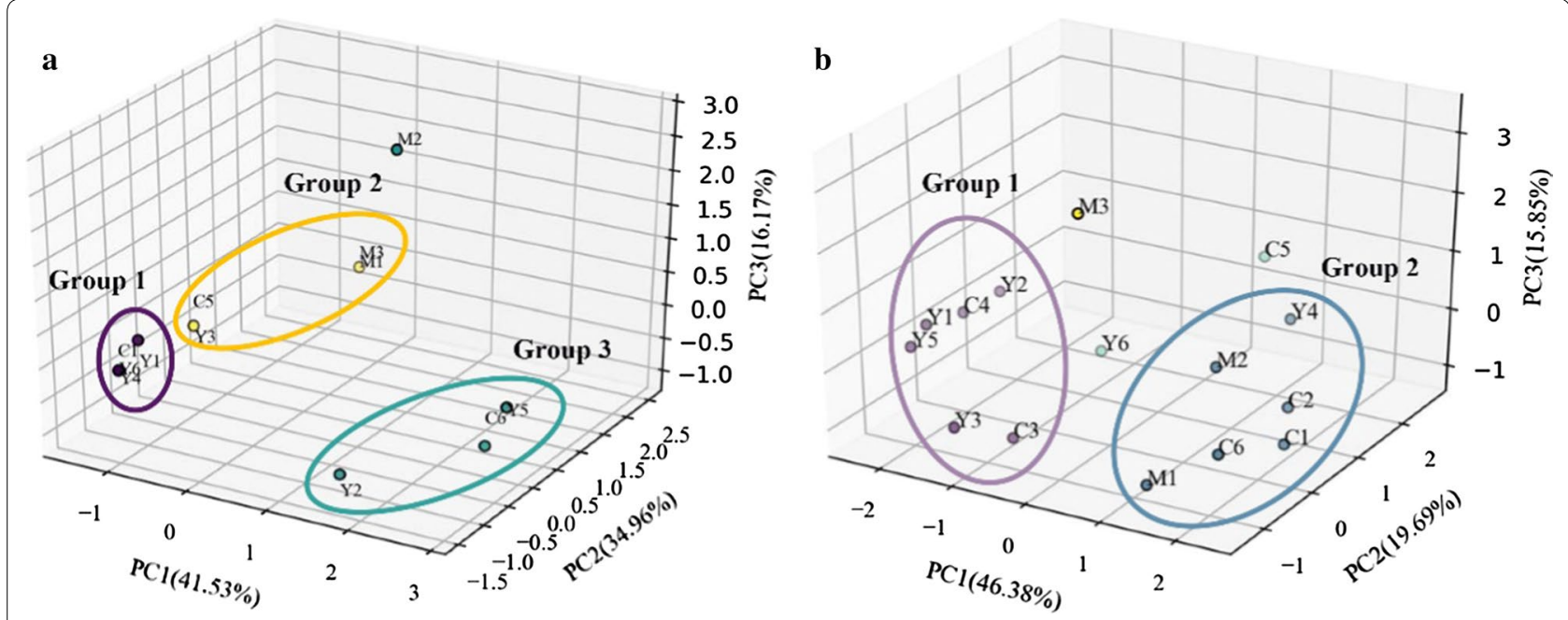

Fig. 6 Principal component analysis for the microplastic compositions in surface water (a) and sediment (b) of the 15 sampling sites

41.53\% of total variance, had high loadings of PP, PE, PA, and $\mathrm{PB} ; \mathrm{PC} 2$ indicated strong contributions of PET and $\alpha$-cellulose; and PC3 was dominated by cellophane. In terms of spatial distribution, some sampling sites overlapped others, with microplastic abundance there being lower and with single polymer types causing high similarities in the same component. Figure $6 \mathrm{~b}$ shows the PCA of the 9 variables in sediment, with $\mathrm{PC} 1, \mathrm{PC} 2$, and $\mathrm{PC} 3$ explaining $>81.92 \%$ of the total variance (component matrix and component plot are shown in Additional file 1: Table S5 and Fig. S4). PC1, explaining $41.53 \%$ of total variance, displayed strong correlations between $\mathrm{PE}$, PU, and PMMA, while PC2 was mainly contributed by PP, $\alpha$-cellulose, and PET, and PC3 with PA, EEA, and CA. Sediment analyses indicate that the sampling sites were divided into two main groups: group 1 comprising sites $\mathrm{Y} 1, \mathrm{Y} 2, \mathrm{Y} 3, \mathrm{Y} 5, \mathrm{C} 3$, and C4; and group two comprising sites M1, M2, C1, C2, C6, and Y4, consistent with the assignment of groups ILR and YRS, reflecting compositional differences between the island and estuary.

\section{Discussion}

\section{Distribution characteristics of microplastics around the Yangtze Estuary}

Chongming Island plays an important role in wildlife migration, providing spawning and feeding grounds for millions of fish and bird species, with physical and toxicological effects of ingested microplastics posing a threat to the coastal ecosystem [31-33]. The abundances of microplastics in surface water at the mouth of the Yangtze River were higher on the east and west corner of Chongming Island (Fig. 1). The highest abundance of all surface water samples $\left(258.9\right.$ items $\left.\mathrm{m}^{-3}\right)$ was at site $\mathrm{Y} 5$, next to the East China Sea, on the eastern shore of Chongming Island, where formed an accumulation zone under the effect of tide and topography. However, this abundance here did not exceed $10.9 \times 10^{3}$ items $\mathrm{m}^{-3}$, which is the highest record in the Yangtze Estuary by Zhao [19].

Table 1 compares microplastic pollution levels in surface water of estuaries in different countries. The average microplastic abundance $\left(67.5 \pm 94.4\right.$ items $\left.\mathrm{m}^{-3}\right)$ in the Yangtze Estuary exceeds that of the Tamar Estuary $\left(0.028\right.$ items $\left.\mathrm{m}^{-3}\right)$, Goiana Estuary $\left(0.14\right.$ items $\left.\mathrm{m}^{-3}\right)$, and five estuaries in South Africa (1.0-7.0 items $\mathrm{m}^{-3}$ ), but is far less than that recorded in polluted estuaries in the USA, Germany, and China ( $>157.2$ items $\mathrm{m}^{-3}$ ). Table 1 is sequenced according to the values of sampling volume and mesh size of different methods. There is an obvious trend that abundance values sharply decreased with the increment of volume and size. Many studies used smallsized sieve in the sampler to further investigate smaller microplastics $(<300 \mu \mathrm{m})$, while it also means less sampling volume ( 1 to $20 \mathrm{~L}$ ) was taken due to a large quantity of tiny particles. Researchers, however, should be cautious that insufficient sampling volume may lead to skeptical results [34], especially when the result is used to represent regional pollution level and compare with others. Inconsistency of units, including items $\mathrm{L}^{-1}$ and items $\mathrm{m}^{-3}$, also makes comparison questionable. For example, there is two orders of magnitude between results in $1 \mathrm{~L}$

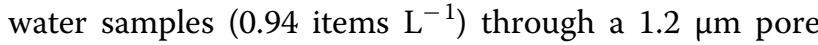
size filter and about ten thousands of liters $330 \mu \mathrm{m}$ net samples $\left(4.5\right.$ items $\left.\mathrm{m}^{-3}\right)$ in results of the Tampa Bay [35]. Given all this, it seems advisable to take sufficiently bulk samples with the use of smaller mesh size, considering 
Table 1 Comparison of floating microplastic abundance and sampling method used in estuaries worldwide

\begin{tabular}{|c|c|c|c|c|c|}
\hline Study estuaries & Location & $\begin{array}{l}\text { Sampling method } \\
\text { and mesh size }(\mu \mathrm{m})\end{array}$ & $\begin{array}{l}\text { Sampling } \\
\text { volume (L) }\end{array}$ & $\begin{array}{l}\text { Abundance } \\
\text { (items } \mathrm{m}^{-3} \text { ) }\end{array}$ & References \\
\hline Tampa Bay & Southeast USA, North America & Water sampler-1.2 & 1 & 940.0 & [35] \\
\hline Charleston Harbor and Winyah Bay & Southeast USA, North America & Water Sampler-63 & 4 & $\begin{array}{l}6600.0 \\
30800.0\end{array}$ & {$[36]$} \\
\hline Charleston Harbor & Southeast USA, North America & Water Sampler-63 & 4 & $2750.0-36500.0$ & {$[37]$} \\
\hline German Baltic coast & Germany, Europe & Water sampler-55 & $5-10$ & $0.0-5000.0$ & [38] \\
\hline Pearl River Estuary & South China, Asia & Water sampler-50 & 20 & 8902.0 & [39] \\
\hline Yangtze Estuary & East China, Asia & Pump-300 & 100 & 67.5 & This study \\
\hline $\begin{array}{l}\text { Mdloti Estuary } \\
\text { uMgeni Estuary } \\
\text { Durban Harbour } \\
\text { Isipingo Estuary } \\
\text { iLovu Estuary }\end{array}$ & South Africa, Africa & Net-300 & 10000 & $\begin{array}{l}1.1 \\
2.5 \\
7.0 \\
3.1 \\
1.0\end{array}$ & {$[40]$} \\
\hline Goiana Estuary & Northeast Brazil, South America & Net-300 & 100000 & 0.1 & {$[41]$} \\
\hline Tampa Bay & Southeast USA, North America & Net-330 & / & 4.5 & {$[35]$} \\
\hline The UK Channel, North, and Celtic Sea area & Northwest Europe & Net-333 & / & $0-1.5$ & {$[42]$} \\
\hline Tamar Estuary & England, Europe & Net-300 & / & 0.028 & {$[43]$} \\
\hline
\end{tabular}

Abundances are expressed as items per cubic meter. The upper parts are small-volume sampling methods, while the lower parts are bulk volume sampling methods.

' $/$ ' means the sampling volume is unknown, nets are often towed at $\sim 2$ knots for a certain time

that results should be accurate and broadly comparable with others.

This is the first study to report microplastic abundances in nearshore waters of the north branch of the Yangtze River. Both branches of the Yangtze Estuary have relatively high abundances of microplastics in surface water due to the Yangtze River's large discharge and plastic flux [44]. It is estimated that 16-20 trillion microplastic particles (i.e., 537.6-905.9 tons) enter the East China Sea via the Yangtze River each year [20]. In the estuaries, the distribution of microplastics is affected by hydrodynamic forces (waves, tides, and currents) in aquatic systems [45, 46]. Plastic particles repeatedly transport offshore and onshore, with some being trapped in enclosed waters [47, 48]. An experiment was conducted on Wadahama Beach to study backwash process of plastics floats. The results showed that the backwashed floats tend to concentrate in the convergence zone under the effect of offshore currents and alongshore currents around the tidal flat [49]. At six estuarine sampling sites (Y1-Y6) on the shores of the Yangtze River, we found various mismanaged plastic waste, including plastic bottles, packaging materials and fishing nets, which may be due to the backwash of the Yangtze River. Inland rivers had a low microplastic abundance $\left(9.8 \pm 12.2\right.$ items $\left.\mathrm{m}^{-3}\right)$ in surface water, with three sampling sites having no detectable microplastics. This is consistent with results of a previous study, which indicated that some sections of urban creeks in Shanghai have low microplastic abundances (80 items $\mathrm{m}^{-3}$ ) [18]. The movement of microplastics may be subject to flow conditions, vegetation patterns, and water levels in particular rivers, which have a significant impact on their transport [50].

Resembling natural colloids and suspended solids, microplastics are subject to turbulent transport, settling, aggregation, biofouling, resuspension and burial, with movement between the water column and sediments [8]. Density is an important factor in vertical transport of microplastics. There were four types of detected polymers, including PE, PP, PB and EEA, whose densities were less than that of water, while the others ( $\alpha$-cellulose, PMMA, PA, PET, PU, Cellophane and CA) were dense than water. Density information is shown in Additional file 1: Table S6. Interestingly, high-density microplastics in surface water of the Yangtze River shores (25.0 \pm 8.4 items $\mathrm{m}^{-3}$ ) were significantly more than (Mann-Whitney $\mathrm{U}$ test, $p=0.008)$ that of inland rivers $(7.8 \pm 13.0$ items $\mathrm{m}^{-3}$ ), while low-density microplastics in sediment of inland rivers $\left(21.7 \pm 16.0\right.$ items $\left.\mathrm{kg}^{-1}\right)$ were significantly more than (Mann-Whitney U test, $p=0.036$ ) that of the Yangtze River shores $\left(5.8 \pm 5.8\right.$ items $\left.\mathrm{kg}^{-1}\right)$. A possible explanation is that high-density particles can reenter the water column by resuspension of bottom sediments [8]. Influenced by nearshore circulation and offshore tides, the sediment resuspension in tidal estuaries contributes to redistribution and exchange of substances between water and sediment phases [51]. By contrast, the rivers on Chongming Island have a low river flow velocity $\left(0.2-0.5 \mathrm{~m} \mathrm{~s}^{-1}\right.$ during drainage periods and more slowly during non-drainage periods), which is conducive to the sedimentation of plastic particles. Many lowdensity microplastics were found in inland sediments. 
This discrepancy could be attributed to change of densities with weathering and biofouling in the environment $[52,53]$. Our results indicate that microplastics are widely distributed in sediments of both groups (overall average abundance $35.0 \pm 15.9$ items $\mathrm{kg}^{-1}$ ), and sediment is regarded as the sink for abundant microplastics in the aquatic environment [54, 55]. Here we have only discussed the influence of density on the sinking of microplastics. Consequently, further research should be undertaken to investigate the sinking behavior more comprehensively.

\section{Uncertainties in alternative methods}

Appropriate sampling and analysis methods are of critical importance in obtaining reliable results. The advantages of our optimized sampling and analysis method are as follows. (1) Sampling and filtration components were made of metal to prevent contamination by plastic materials. (2) At least $100 \mathrm{~L}$ water was sampled at each site, as bulk volumes were considered to provide reliable and representative results. (3) Microplastics usually float on the surface of water, so suction from the surface allows collection of surrounding particles, with pumping improving in situ filtration efficiency. (4) All suspected microplastic particles were identified by $\mu$-FTIR, with potential errors arising if a limited number of randomly selected particles are analyzed.

Compositional errors can be significant if a limited number of particles were randomly selected to identify their composition $[28,29]$. For example, fiber is a common type of microplastics, accounting for $33 \%$ in surface water and $67 \%$ in sediments from Chongming Island. This prevalent shape is matched with various polymer compositions including $\alpha$-cellulose, PA, PET, PMMA, PP and $\mathrm{PE}$ (the latter two only in sediment). However, there are many natural materials such as chipboard, cotton, and natural cellulose with fiber shapes, and it is difficult to distinguish between polymer and natural fibers, even spectroscopically, because some polymer fibers are cellulose-based and their FTIR spectra are almost identical to those of natural fibers [56]. Here, 137 fibers were selected using the microscope, but only 87 (63.5\%) were identified as microplastics according to their spectral characteristics, color, and shape. Further analysis is therefore required to determine whether or not fibers should be recorded as microplastics.

Density separation and digestion are common processes of sample processing in many studies $[9,16]$, but can lead to incomplete sample transfer. Some particles and fibers are easily stuck to the beaker wall and glass rod when stirring solutions, however, these tiny items are often neglected by operators. Peroxide digestion causes bleaching of particles and may produce different organic materials in some cases $[23,57]$. We therefore applied visual sorting directly on the metal filters, without involving density separation and digestion steps. In order to withstand hydraulic pressure by suction of the pump, metal filters were woven from wires with diameter of $100 \mu \mathrm{m}$ and designed as the multi-layer structure. Because of this structure, here we used the mesh size of $300 \mu \mathrm{m}$, which is larger than that used by other studies $(<100 \mu \mathrm{m})$. In the future, we hope to reduce the mesh size of metal filters, and thus further improve the performance of the microplastic sampler and decrease the lower limit for sampling.

\section{Conclusions}

Microplastics are ubiquitous in freshwater environments but, compared to marine environments, few reliable bulk-sampling methods are available for their study. This study aims to assess microplastic pollution in surface water and sediments of the Yangtze Estuary, including inland rivers on Chongming Island and the lower reaches of the Yangtze River. A modified bulk water-sampling method, having advantages of low-cost, high efficiency and anti-contamination, was employed and well applicable to various freshwater environments. Results indicate that microplastics are much more abundant in surface water in the Yangtze Estuary than in the inland rivers, while sediment contamination levels were similar. Compositional differences of microplastics between the island and estuary exist especially in sediments; in addition, significant density differences between surface water and sediments verifies the diverse vertical transport of microplastics in inland rivers and the estuary, where resuspension of sediments directly influenced redistribution in both phases. We suggest that microplastics monitoring of both phases should be conducted by suitable means, with further studies of the sinking behavior in the Yangtze Estuary being required.

\section{Supplementary information}

Supplementary information accompanies this paper at https://doi. org/10.1186/s12302-020-0297-7.

Additional file 1: Table S1. Sampling information and analysis results of all sampling sites in the Yangtze Estuary. Table S2. Detailed information of non-plastic particles found on the filter. Table S3. Comparison of different sized MPs. Table S4. Component matrix of surface water data. Table S5. Component matrix of sediment data. Table S6. Density information of identified polymers in this study. Figure S1. Map of sampling sites. Figure S2. Flow diagram of sample's transportation. Figure S3. Component plot of surface water data. Figure S4. Component plot of sediment data

Abbreviations

$\mu$-FTIR: Micro-Fourier-transform infrared spectroscopy; PCA: Principal component analysis; SPSS: Statistic package for social science; YRS: Yangtze River shores; ILR: Inland rivers; PE: Polyethylene; PP: Polypropylene; PET: Polyethylene terephthalate; PA: Polyamide; PB: Polybutene; PU: Polyurethane; PMMA: Polymethyl methacrylate; EEA: Ethylene/ethyl acrylate; CA: Cellulose acetate. 


\section{Acknowledgements \\ Not applicable.}

\section{Authors' contributions}

$Y L, J W, C C$ and $H Z$ were involved in the sampling and experiments. YL and $Z L$ wrote the manuscript. YL, ZL and HZ designed the study. All authors read and approved the final manuscript.

\section{Funding}

This work was supported by the Norwegian Research council program INTPART (PLASTPOLL 275172).

\section{Availability of data and materials}

The datasets obtained and analyzed during the current study are available from the corresponding author on reasonable request.

\section{Ethics approval and consent to participate}

Not applicable.

\section{Consent for publication}

Not applicable.

\section{Competing interests}

The authors declare that they have no competing interests.

\section{Author details}

${ }^{1}$ College of Environmental Science and Engineering, Tongji University, Shanghai 200092, China. ${ }^{2}$ State Key Laboratory of Pollution Control and Resource Reuse, Tongji University, Shanghai 200092, China. ${ }^{3}$ State Key Laboratory of Pollution Control and Resource Reuse, School of the Environment, Nanjing University, Nanjing 210023, China.

Received: 19 November 2019 Accepted: 24 January 2020

Published online: 07 February 2020

\section{References}

1. Plastics Europe, Plastics - the facts 2019, an analysis of european plastics production, demand and waste data. 2019, Plastics Europe, Brussels, Belgium

2. Arthur C, Baker J, Bamford H (2009) In: Proceedings of the international research workshop on the occurrence, effects and fate of micro-plastic marine debris, Sept 9-11, 2008. 2009: NOAA Technical Memorandum NOS-OR\&R-30

3. Carpenter EJ et al (1972) Polystyrene spherules in coastal waters. Science 178(4062):749-750

4. Cozar A et al (2014) Plastic debris in the open ocean. Proc Natl Acad Sci USA 111(28):10239-10244

5. Peng $X$ et al (2018) Microplastics contaminate the deepest part of the world's ocean. Geochem Perspect Lett 9:1-5

6. Lusher AL et al (2015) Microplastics in Arctic polar waters: the first reported values of particles in surface and sub-surface samples. Sci Rep 5:1947

7. Waller CL et al (2017) Microplastics in the Antarctic marine system: an emerging area of research. Sci Total Environ 598:220-227

8. Lambert S, Wagner M (2018) Microplastics are contaminants of emerging concern in freshwater environments: an overview. In: Wagner M, Lambert $\mathrm{S}$ (eds) Freshwater microplastics: emerging environmental contaminants. Springer International Publishing, Cham, pp 1-23

9. Li JY, Liu HH, Chen JP (2018) Microplastics in freshwater systems: a review on occurrence, environmental effects, and methods for microplastics detection. Water Res 137:362-374

10. Murphy F et al (2016) Wastewater treatment works (WwTW) as a source of microplastics in the aquatic environment. Environ Sci Technol 50(11):5800-5808

11. Nizzetto L, Langaas S, Futter M (2016) Pollution: do microplastics spill on to farm soils? Nature 537(7621):488

12. He P et al (2019) Municipal solid waste (MSW) landfill: a source of microplastics? -Evidence of microplastics in landfill leachate. Water Res 159:38-45
13. Dris R et al (2016) Synthetic fibers in atmospheric fallout: a source of microplastics in the environment? Mar Pollut Bull 104(1-2):290-293

14. Wei W et al (2019) Polyvinyl chloride microplastics affect methane production from the anaerobic digestion of waste activated sludge through leaching toxic bisphenol-A. Environ Sci Technol 53(5):2509-2517

15. Silva PPGE et al (2016) Leachate from microplastics impairs larval development in brown mussels. Water Res 106:364-370

16. Hidalgo-Ruz V et al (2012) Microplastics in the marine environment: a review of the methods used for identification and quantification. Environ Sci Technol 46(6):3060-3075

17. Lebreton LCM et al (2017) River plastic emissions to the world's oceans. Nat Commun 8:15611

18. Luo WY et al (2019) Comparison of microplastic pollution in different water bodies from urban creeks to coastal waters. Environ Pollut 246:174-182

19. Zhao SY et al (2014) Suspended microplastics in the surface water of the Yangtze Estuary System, China: first observations on occurrence, distribution. Mar Pollut Bull 86(1-2):562-568

20. Zhao SY et al (2019) Analysis of suspended microplastics in the Changjiang Estuary: implications for riverine plastic load to the ocean. Water Res 161:560-569

21. Peng GY et al (2017) Microplastics in sediments of the Changjiang Estuary China. Environ Pollut 225:283-290

22. Xu P et al (2018) Microplastic risk assessment in surface waters: a case study in the Changjiang Estuary China. Mar Pollut Bull 133:647-654

23. Hurley R, Woodward J, Rothwell JJ (2018) Microplastic contamination of river beds significantly reduced by catchment-wide flooding. Nat Geosci 11(4):251

24. Cole M et al (2011) Microplastics as contaminants in the marine environment: a review. Mar Pollut Bull 62(12):2588-2597

25. Zhang EF et al (2011) Analytical solution for salt intrusion in the Yangtze Estuary China. Estuar Coastal Shelf Sci 91(4):492-501

26. Waldschlager K, Schuttrumpf H (2019) Effects of particle properties on the settling and rise velocities of microplastics in freshwater under laboratory conditions. Environ Sci Technol 53(4):1958-1966

27. Bergmann M et al (2017) High quantities of microplastic in Arctic deepsea sediments from the HAUSGARTEN observatory. Environ Sci Technol 51(19):11000-11010

28. Shim WJ, Hong SH, Eo SE (2017) Identification methods in microplastic analysis: a review. Anal Methods 9(9):1384-1391

29. Song YK et al (2015) A comparison of microscopic and spectroscopic identification methods for analysis of microplastics in environmental samples. Mar Pollut Bull 93(1-2):202-209

30. Cai HW et al (2019) A practical approach based on FT-IR spectroscopy for identification of semi-synthetic and natural celluloses in microplastic investigation. Sci Total Environ 669:692-701

31. Spear LB, Ainley DG, Ribic CA (1995) Incidence of plastic in seabirds from the tropical pacific, 1984-1991 — relation with distribution of species, sex age, season year and body-weight. Mar Environ Res 40(2):123-146

32. Zhao B et al (2004) An ecosystem service value assessment of land-use change on Chongming Island China. Land Use Policy 21(2):139-148

33. Peters CA, Bratton SP (2016) Urbanization is a major influence on microplastic ingestion by sunfish in the Brazos River Basin, Central Texas, USA Environ Pollut 210:380-387

34. Tamminga M, Hengstmann E, Fischer EK (2018) Microplastic analysis in the South Funen Archipelago, Baltic Sea, implementing manta trawling and bulk sampling. Mar Pollut Bull 128:601-608

35. McEachern Ket al (2019) Microplastics in Tampa Bay, Florida: abundance and variability in estuarine waters and sediments. Mar Pollut Bull 148:97-106

36. Gray AD et al (2018) Microplastic in two South Carolina Estuaries: occurrence, distribution, and composition. Mar Pollut Bull 128:223-233

37. Leads RR, Weinstein JE (2019) Occurrence of tire wear particles and other microplastics within the tributaries of the Charleston Harbor Estuary, South Carolina, USA. Mar Pollut Bull 145:569-582

38. Stolte A et al (2015) Microplastic concentrations in beach sediments along the German Baltic coast. Mar Pollut Bull 99(1-2):216-229

39. Yan MT et al (2019) Microplastic abundance, distribution and composition in the Pearl River along Guangzhou city and Pearl River estuary China. Chemosphere 217:879-886 
40. Naidoo T, Glassom D, Smit AJ (2015) Plastic pollution in five urban estuaries of KwaZulu-Natal South Africa. Mar Pollut Bull 101(1):473-480

41. Lima ARA, Barletta M, Costa MF (2015) Seasonal distribution and interactions between plankton and microplastics in a tropical estuary. Estuar Coast Shelf Sci 165:213-225

42. Maes T et al (2017) Microplastics baseline surveys at the water surface and in sediments of the North-East Atlantic. Front Mar Sci 4:135

43. Sadri SS, Thompson RC (2014) On the quantity and composition of floating plastic debris entering and leaving the Tamar Estuary Southwest England. Mar Pollut Bull 81(1):55-60

44. Cheung PK, Cheung LTO, Fok L (2016) Seasonal variation in the abundance of marine plastic debris in the estuary of a subtropical macro-scale drainage basin in South China. Sci Total Environ 562:658-665

45. Vermeiren P, Munoz CC, Ikejima K (2016) Sources and sinks of plastic debris in estuaries: a conceptual model integrating biological, physical and chemical distribution mechanisms. Mar Pollut Bull 113(1-2):7-16

46. Krelling AP et al (2017) Transboundary movement of marine litter in an estuarine gradient: evaluating sources and sinks using hydrodynamic modelling, and ground truthing estimates. Mar Pollut Bull 119(1):48-63

47. Mathalon A, Hill P (2014) Microplastic fibers in the intertidal ecosystem surrounding Halifax Harbor Nova Scotia. Mar Pollut Bull 81(1):69-79

48. Fok $L$ et al (2017) Size distribution of stranded small plastic debris on the coast of Guangdong South China. Environ Pollut 220:407-412

49. Hinata $\mathrm{H}$ et al (2017) An estimation of the average residence times and onshore-offshore diffusivities of beached microplastics based on the population decay of tagged meso- and macrolitter. Mar Pollut Bull 122(1-2):17-26

50. Balas CE et al (2001) A statistical riverine litter propagation model. Mar Pollut Bull 42(11):1169-1176

51. Shi Z, Ren LF, Lin HL (1996) Vertical suspension profile in the Changjiang Estuary. Mar Geol 130(1-2):29-37

52. Moret-Ferguson S et al (2010) The size, mass, and composition of plastic debris in the western North Atlantic Ocean. Mar Pollut Bull 60(10):1873-1878

53. Long M et al (2015) Interactions between microplastics and phytoplankton aggregates: impact on their respective fates. Mar Chem 175:39-46

54. Matsuguma Y et al (2017) Microplastics in sediment cores from Asia and Africa as indicators of temporal trends in plastic pollution. Arch Environ Contam Toxicol 73(2):230-239

55. Ding L et al (2019) Microplastics in surface waters and sediments of the Wei River, in the Northwest of China. Sci Total Environ 667:427-434

56. Peeken l et al (2018) Arctic sea ice is an important temporal sink and means of transport for microplastic. Nat Commun 9:1-2

57. Cole M et al (2014) Isolation of microplastics in biota-rich seawater samples and marine organisms. Sci Rep 4:4528

\section{Publisher's Note}

Springer Nature remains neutral with regard to jurisdictional claims in published maps and institutional affiliations.

\section{Submit your manuscript to a SpringerOpen ${ }^{\circ}$ journal and benefit from:}

- Convenient online submission

Rigorous peer review

- Open access: articles freely available online

- High visibility within the field

- Retaining the copyright to your article

Submit your next manuscript at springeropen.com 